\title{
An Efficient Human Identification on the Biometric Gait Recognition System using the Inner Angle of the Triangle
}

\author{
Monika Jhapate \\ M. Tech \\ Radharaman Engineering College, \\ Bhopal
}

\author{
Mukesh Dixit \\ Assistant Professor \\ Radharaman Engineering College, \\ Bhopal
}

\begin{abstract}
Gait based human recognition system is most important and attractive method of biometrics. Gait the way of walking capture from distance and provide more efficient means of verification. In this paper, we propose an efficient algorithm which works on angle based technique. Initially video converted into frames and then feature abstraction is done. Here we are taking three lower body parts for recognition and a correlation of triangle is derived. Using cosine formula each inner angle of triangle is calculated and stored in database for identification. The gait system is designed using MATLAB to accomplish this research work.
\end{abstract}

\section{Keywords}

Biometrics, Image processing, Gait recognition, Pattern Recognition, Security.

\section{INTRODUCTION}

Biometrics is term by which a person can be uniquely identified by his physiological or behavioral traits. The term gait recognition to signify the identification of an individual from a video sequence of the subject walking. Unique identity is most important feature of security in the world. Biometrics refers the unique identification as per behavior and physiological. In this work we are using one type of behavioral identification system that is gait. Gait means a person's way of waking. The very important features of gait are distance from camera and without knowledge of person.

In this paper we discus about angle based gait recognition. Static images of CASIA A dataset are taken for so the results. Here, lower body position both feet a viewing hand are taken as a feature abstraction.

\section{RELATED WORK}

Gait recognition work is based on static and dynamic parts of images. Static part means the body parts which usually did not move when a person walk (upper body part like head, chest) and dynamic means which parts moves when a person is walk (Lower body part hand, legs). Many researchers used static part or dynamic part for recognition and many researchers used both parts for recognition. The most common and effective method using Gait Energy Image (GEI), silhouette image and motion contour Image (MCI) as gait representation. MCI, GEI and silhouette image that captures not only static but also motion characteristic of gait. In the field of this a lots of work is done on dynamic portion [paper] like triangle based techniques many researcher work on this part. Position joint base human body detection gives the correct classification rate of 90 percent [2]. Angels based gait detection Gait Recognition with Geometric Characteristic and Fuzzy Logic uses fuzzy concept on the dynamic part and obtained CCR 90 percent [3]. A Novel Method of Gait Recognition Using Fuzzy Inference System is also used the dynamic feature of human for recognition.

\section{GAIT SYSTEM}

Gait recognition system is multistage work which perform on many steps as shown in figure first video sequence is captured by camera where camera position is decided that all portion of human is covered and most important that it captured at least one gait cycle figure 2. Second step convert video into images for one cycle that is called gait cycle, in third part feature extraction is done, then classifier check the result in database and show it if new person match with stored then print result that person is match otherwise ask for store that Do you Want to store or not.

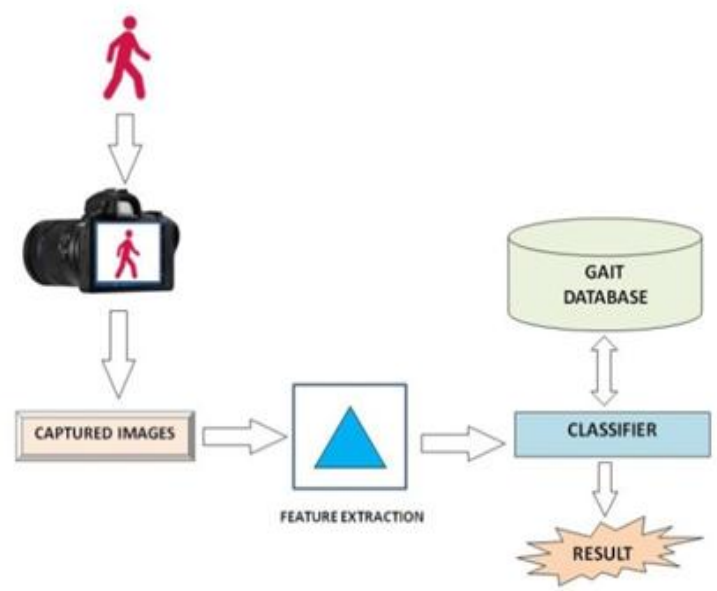

Figure 1: Gait Cycle System

Gait cycle is shown in figure 2 each cycle is divided into two portion stance and swing. Stance covers 60 percent of gait from initial contact to toe off and swing phase covers 40 percent of gait from toe off to again initial contact this cycle are repeated.

Gait cycle is shown in figure 2 the gait cycle is also called stride and each cycle is divided into two portion stance and swing. Stance covers 60 percent of gait from initial contact to toe off and swing phase covers 40 percent of gait from toe off to again initial contact this cycle are repeated. 


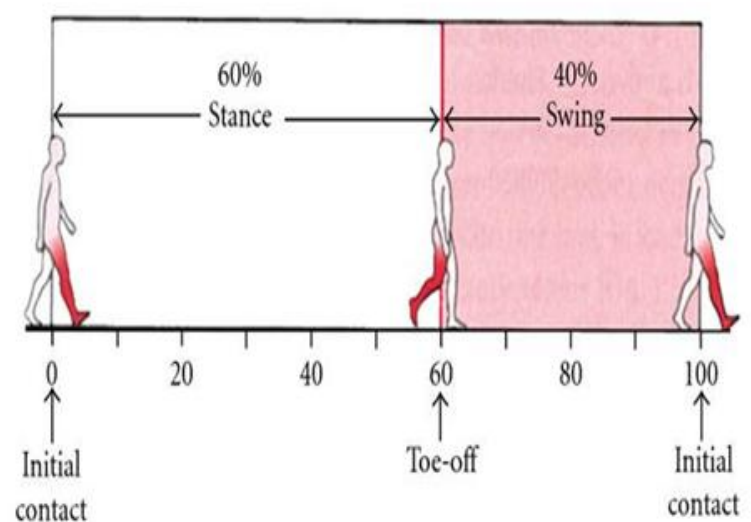

Figure 2: Gait Cycle with Stance and Swing

\section{PROPOSED WORK}

In our proposed work we are taking lower body part for recognition. As shown in figure 3 we are taking both feet and hand after feature extraction one triangle is formed. For these triangle inner angles values are calculating with the help of cosine formula.
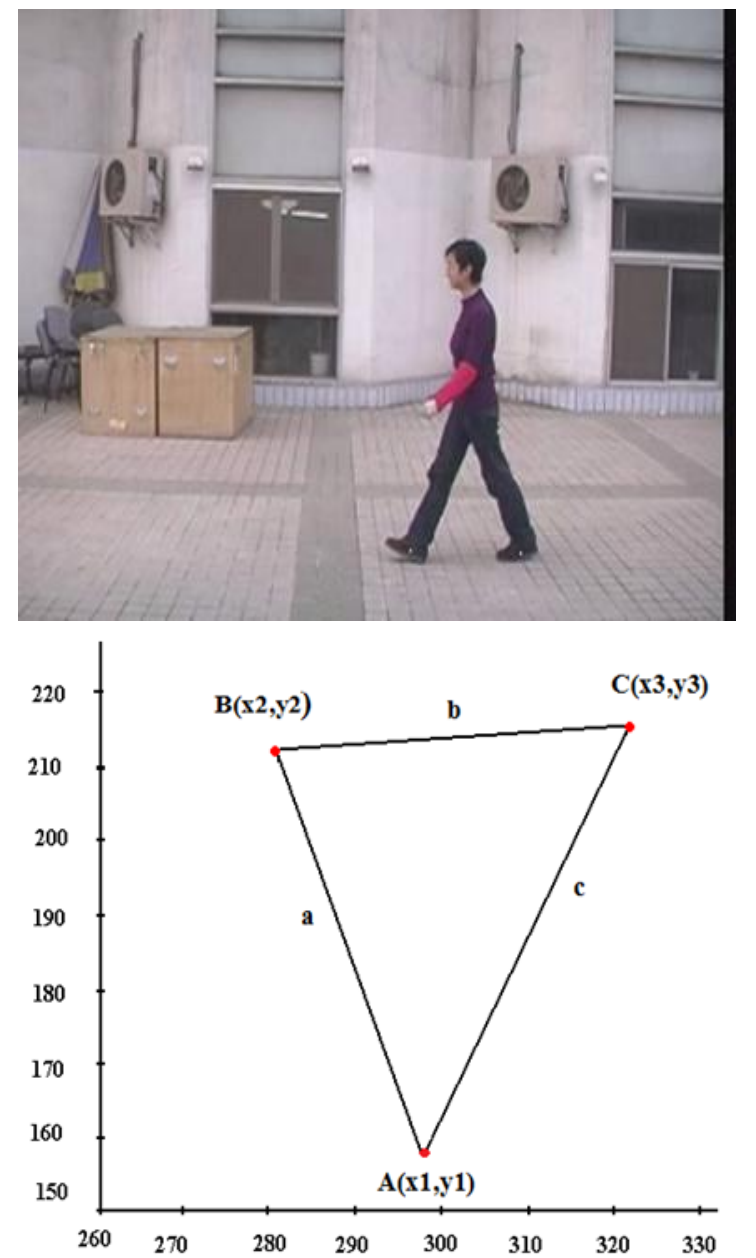

Figure 3: Image and after feature extraction Triangle $\mathrm{ABC}$ after connecting points

\section{PROPOSED ALGORITHM}

1. Take an input video for one cycle.

2. Convert video into frames (colored).

3. Convert each colored frame into gray scale.

4. Extract pixel values $(\mathrm{x} 1, \mathrm{y} 1),(\mathrm{x} 2, \mathrm{y} 2)$ and $(\mathrm{x} 3, \mathrm{y} 3)$ which are values of Hand, Right feet and Left feet.

5. Construct logical triangle between pixel values of each desired frame.

6. Calculate angles of a triangle by formula.

7. Calculate mean of each angle $(\Theta 1, \Theta 2, \Theta 3)$ for one cycle.

8. Print the result of mean.

9. Exit.

Here ABC triangle is created between coordinate points ( $\mathrm{x} 1$, $\mathrm{y} 1),(\mathrm{x} 2, \mathrm{y} 2)$ and $(\mathrm{x} 3, \mathrm{y} 3)$ where $\mathrm{x} 1, \mathrm{x} 2, \mathrm{x} 3$ and $\mathrm{y} 1, \mathrm{y} 2, \mathrm{y} 3$ represents pixel values. Angles are $\mathrm{BAC}, \mathrm{ABC}$ and $\mathrm{ACB}$. Point A represents hand point, point $\mathrm{B}$ represents left feet and $\mathrm{C}$ represents right feet. Then we calculate edges of triangle $\mathrm{AB}, \mathrm{BC}$ and $\mathrm{CA}$ the value is respectively $\mathrm{a}, \mathrm{b}$ and $\mathrm{c}$ by following a formula:

$$
\begin{aligned}
& a=\operatorname{sqrt}((x 2-x 1) 2+(y 2-y 1) 2) \\
& b=\operatorname{sqrt}((x 3-x 2) 2+(y 3-y 2) 2) \\
& c=\operatorname{sqrt}((x 3-x 1) 2+(y 3-y 1) 2)
\end{aligned}
$$

Here we represent angles $\mathrm{BAC}, \mathrm{ABC}$ and $\mathrm{ACB}$ by respectively by $\Theta 1, \Theta 2, \Theta 3$ we calculate angles of triangle by cosine and sine formula as follows.

By cosine formula:

$$
\Theta 2=\cos -1((\mathrm{a} 2+\mathrm{c} 2-\mathrm{b} 2) / 2 * \mathrm{a} * \mathrm{c})
$$

// Computing second angle

By sine formula:

$$
\begin{aligned}
& \text { a/ } \operatorname{Sin} \Theta 1=b / \sin \Theta 2=c / \sin \Theta 3 \\
& \text { So } \\
& \Theta 3=\sin -1((c * \sin \Theta 2) / b)
\end{aligned}
$$

//Computing third angle

By triangle property

$\Theta 1+\Theta 2+\Theta 3=180$

Then

$$
\Theta 1=180-\Theta 2-\Theta 3
$$

// Computing first angle

\section{PROPOSED FLOW CHART}

This flow chart show the work is done in different section from video capture to result. First video is captured and feature extraction on the basis of lower body part is done and then result is generated with the help of algorithm. 


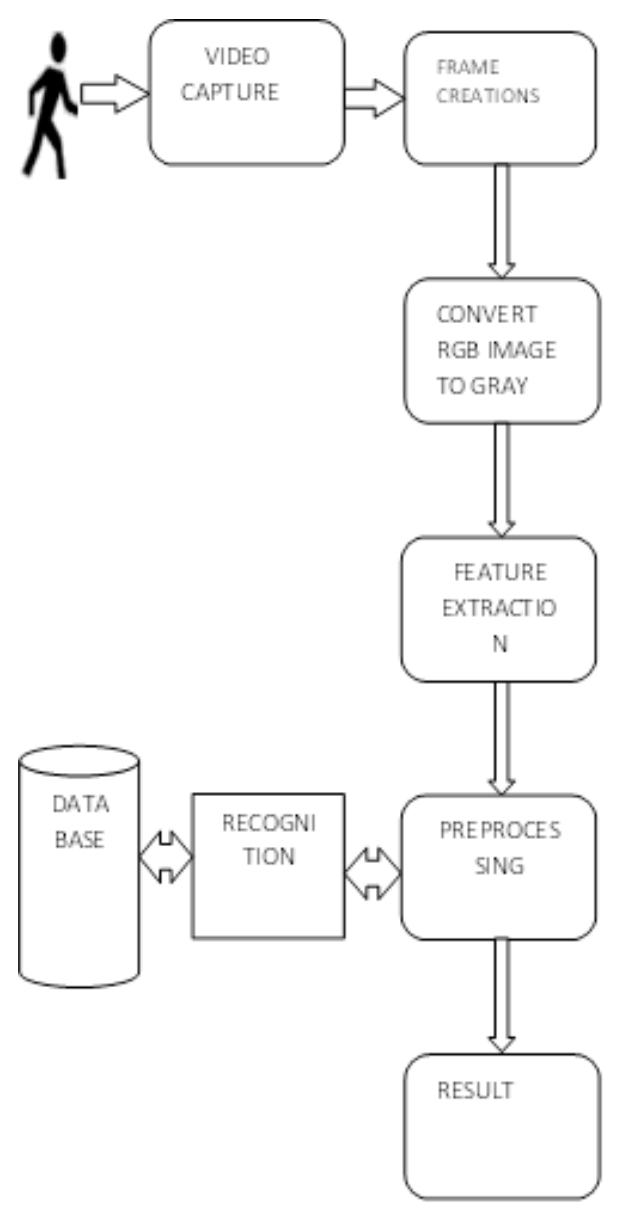

Figure 4: Flow Chart

\section{RESULT}

We used CASIA A data set for our experiments here we used 15 different subject and check identification of uniqueness. Our result is shows that unique identification is done with 90 percent CCR

\begin{tabular}{|c|c|c|c|}
\hline \multicolumn{4}{|c|}{2 Comenal Wines } \\
\hline & & & \\
\hline \multicolumn{4}{|c|}{ 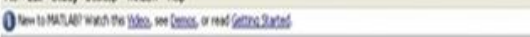 } \\
\hline treve & fatm_lagie & Sectad_Laghe & arrid_legin \\
\hline 1 & 7.:190 & 6.6\% & s.. 160 \\
\hline 2 & ท.เม & 5.640 & 45.74s \\
\hline 1 & 73.1127 & 9.9.341 & 45.760? \\
\hline i & 6.795? & ร9.าก & 45.1995 \\
\hline 3 & 80.05*6 & 7..2466 & 46.7570 \\
\hline 6 & 90.237 & พ..616 & 4.790? \\
\hline ? & ง.7.15? & r.csss & 45.804 \\
\hline 1 & ท.ม1s & ต..2.6 & 30.7007 \\
\hline , & $\omega .6 s 2$ & ต.า. & 3.580 \\
\hline 10 & $\$ 0.000 \%$ & so.uss & natsi \\
\hline "11 & พ4.าท & ง.,.35! & 27.53:2 \\
\hline n & ห.62\% & 4..1307 & 2.ต1 \\
\hline 1 & 7ร.093 & 4.053: & 23.0609 \\
\hline 14 & 79.s:日s & 44.005! & ж.7.ม: \\
\hline is & 0..2966 & 44.5948 & 16.640 \\
\hline 16 & *..sss & 45. 7000 & 36.6506 \\
\hline 17 & \%..2595 & 4.2.24 & 13.0801 \\
\hline is & 6..2ass & 6.:26ss & แ.69 \\
\hline 3 & 6.674 & \&.4:0s & 9.261 \\
\hline 10 & 08.4000 & 0.052: & 19.9296 \\
\hline a & 05.4974 & 6.4262 & 23,040 \\
\hline 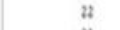 & 0..070 & พ..11 & 41.1694 \\
\hline$"$ & n.4510 & 8.0280 & 4.4.4" \\
\hline $\begin{array}{l}\text { mes What.. } \\
\| 1\end{array}$ & צ..274 & 36.6\% & 13.1960 \\
\hline
\end{tabular}

Figure 5: Table shows the experimental results of a particular subject

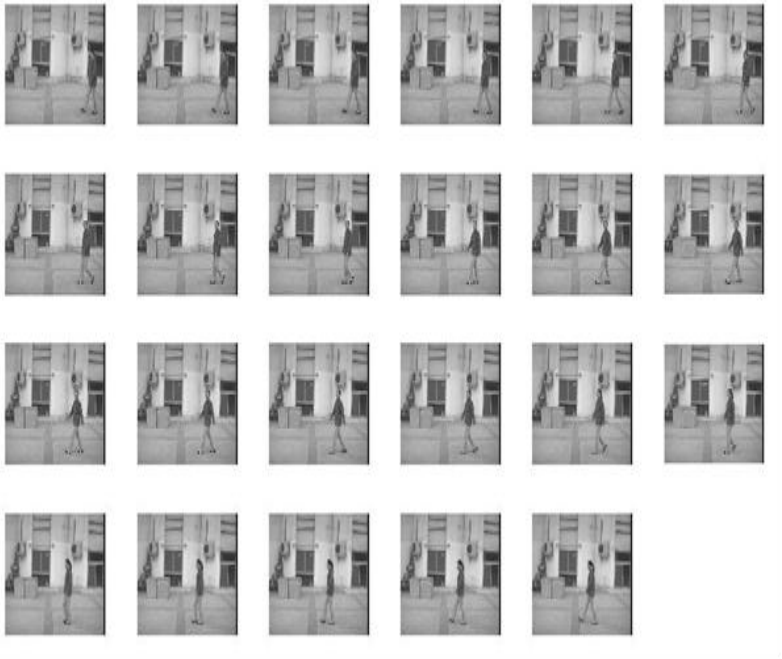

Figure 6: Shows multiple frames of Gait Cycle

8. CONCLUSION AND FUTURE WORK

In this work two dynamic feature of human (hand and feet) taken as a feature extraction. Here triangle is generated and inner angle of triangle is calculated with cosine formula. We used Matlab tool to implement our work with CASIA A data set and generated result. In our work the correct classification rate is $90 \%$ which is better than some other method.

Technology never stop for future we can apply this method for upper body parts or with other body parameter for identification our work is fix for CASIA A data set only.

\section{REFERENCES}

[1] Jyoti Bharti, M. K. Gupta, "Gait Recognition with Geometric Characteristic and Fuzzy Logic", Canadian Journal on Image Processing and Computer Vision Vol. 3 No. 1, March 2012.

[2] Xuelong Li, Stephen J. Maybank,Shuicheng Yan, Dacheng Ta, and Dong Xu,"Gait Components and TheirApplication to Gender Recognition", IEEE Transactions on Systems, Man, and Cybernetics, Part C Applications and Reviews, vol. 38, no. 2, March 20.

[3] D.M.Gavrila, The visual analysis of human movement: a survey, Computer Vision and Image Understanding, Vol. 73, no.1, January, pp.82-98, 1999.

[4] AI-Hua Wang, ji-Wei Liu, A gait recognition method based on positioning human body joints, proceedings of the 2007 international conference on wavelet analysis and pattern recognition, Beijing, China, 2-4 Nov, 2007.

[5] Arun Kumar Jhapate, Jasvinder Pal Singh, Gait Based Human Recognition System using Single Triangle IJCST Vol. 2, Issue 2, June 2011 ISSN : 2229 - 433 ( Print )| ISSN : 0976-8491 (Online )

[6] Jasvinder Pal Singh, Sanjay Agrawal, An approach for human gait identification based on area, IOSR Journal of Computer Engineering (IOSR-JCE) e-SSN: 2278-0661, p- ISSN: 2278-8727Volume 10, Issue 3 (Mar. - Apr. 2013), PP 43-47.

[7] Mr. Atul Raghuwanshi Mr. Jayesh Surana, A Novel Method of Gait Recognition Using Fuzzy Inference System, International Journal Of Research In Advance 
Technology In Engineering (IJRATE) Volume 2, Issue 3, June 2014, ISSN: 2347 - 7806.

[8] Nikolaos V. Boulgouris, Dimitrios Hatzinakos, and Konstantinos N. Plataniotis, A challenging signal processing technology for biometric identification, IEEE Signal Processing Magazine,Vol-22, No- 6 pp 78-90, November 2005.

[9] James R. Gage, Peter A. Deluca, Thomas S. Renshaw, Gait Analysis Principles and Applications, The Journal of bone and joint surgery, vol. 77,1607-1623, 1995.
[10] Xuelong Li, Stephen j. Maybank, switching Yan, dancing too, and Dong $\mathrm{Xu}$, gait components and their application to gender recognition, IEEE transactions on systems, man, and cybernetics-part c: applications and reviews, vol. 38, no. 2, march 2008 .

[11] Ryuhei Okuno, Satoshi Fujimoto, Jun Akazawa, Masaru Yokoe, Saburo Sakoda and Kenzo Akazawa, 30th Annual International IEEE EMBS Conference Vancouver, British Columbia, Canada, August 20-24, 2008. 